\title{
Introducción
}

\section{Mercados precarios, poblaciones vulnerables y arreglos familiares}

\author{
Mirza Aguilar Pérez \\ María de Lourdes Flores Morales \\ Benemérita Universidad Autónoma de Puebla (BUAP)
}

Recepción: 23 de noviembre de 2016 Aceptación: 2 de marzo de 2017

$\mathrm{E}$

1 presente trabajo discute, desde una perspectiva muldisciplinaria, los procesos que generan acumulación de desventajas sociales, que a su vez pueden desencadenar procesos de vulnerabilidad en diversos grupos de población. Nos interesa analizar específicamente los efectos de la precarización de los mercados de trabajo en los hogares y de la precarización de las condiciones de vida experimentadas por las familias.

Consideramos que dichas tendencias son parte de un proceso global que obedece a un régimen extensivo e intensivo de explotación laboral, y de los despojos estructurales en el siglo xxi (Harvey, 2004). La vulnerabilidad está relacionada con el grado de disponibilidad y posesión de recursos y relaciones, que contemplan la capacidad de trabajo, vivienda y relaciones familiares, entre otros aspectos, así como las estrategias para su manejo (García, 2011). Por exclusión laboral, retomamos parte de la propuesta de García (2011), como la existencia de un excedente laboral constituido por los desempleados estructurales, los autoempleados de subsistencia, los asalariados en precariedad extrema y los migrantes internacionales.

García considera que no son parte afuncional para los propósitos del capital. Sin embargo, a contracorriente de su propuesta, consideramos que son parte de una sobrepoblación relativa, que sobra en los mercados laborales. Los contingentes del ejército industrial desechable: flotantes, latentes u obsoletos, son funcionales en una etapa de sobreacumulación de capital. No consideramos que sean innecesarios, prescindibles y afuncionales al capital.

En este tenor, la exclusión laboral es parte de un proceso de deslaborización, la cual ha sido uno de los logros de la actual reforma laboral en México. Entendemos por deslaborización el proceso por el cual el capital y el Estado han avanzado en la reestructuración de la ley del trabajo en una serie de concesiones en que la figura del trabajador ha pasado a ser la de un prestador de servicios (out sourcing, putting out system, etc.). Celis y Valencia (2011) la definen como la capacidad de las empre- 
sas para eludir el derecho valiéndose de la intermediación laboral y la subcontratación, con lo que una relación laboral se convierte en una compraventa de servicios, regulada por el derecho civil. Un caso especial es la figura de las cooperativas, en las que en la contratación de trabajadores aparece la empresa como vendedora de servicios, eliminando así el trabajo de sus afiliados (Celis y Valencia, 2011).

Aunque es de resaltar que, para el caso de México, con la reforma laboral de 2012 se ha legitimado y legislado un régimen de flexibilización que atenta contra las conquistas logradas por los trabajadores y las trabajadoras (De la Garza, 2015).

Por otra parte, la perspectiva de la que partimos es una crítica a los estudios que han realizado una minuciosa caracterización de los mercados de trabajo y de los trabajadores en el contexto neoliberal. La catalogación acentúa que no todo lo atípico o inestable es precario (Pacheco, De la Garza \& Reygadas, 2011). Sin embargo, entre lo que es o no un mercado laboral típico, atípico o clásico - tipologías sugeridas por la Organización Internacional del Trabajo (OIT), la Ley Federal del Trabajo y por académicos-, se ilustran en el fondo diversos mecanismos de explotación y autoexplotación laboral. En el caso de los y las trabajadoras domésticas, la Ley Federal del Trabajo los nombra como "trabajadores especiales", modalidad que vuelve imprecisos los derechos y las obligaciones del empleador y del empleado, como lo son, por mencionar algunas, la jornada laboral y la atención a la seguridad social. Dejan al libre albedrío tanto la jornada como el salario de estos "trabajadores especiales". ${ }^{1}$ Guadarrama, Hualde y López consideran que son hasta ahora herramientas conceptuales con las que se cuenta para definir en negativo a los mercados laborales que se alejan de un modelo ideal, por lo que se requiere un mayor análisis de dichas categorías (2012, p.214).

La supuesta mayor libertad, la libre elección y la menor vigilancia que los trabajadores experimentan en el espacio laboral es parte de un discurso políticamente correcto (Hall, 2015), sin que por ello se limite la acumulación de capital. ${ }^{2}$ En la

"La legislación en materia de trabajadores domésticos ha sido elaborada en 1931 y sigue vigente. En la Ley Federal del Trabajo (LFT), los derechos y obligaciones de los trabajadores domésticos y de sus empleadores se exponen en un apartado especial, dentro de la categoría de 'trabajadores especiales', lo cual instituye una diferencia entre estos trabajadores y el resto. Además, los derechos enunciados en los artículos 331 a 339 son imprecisos; por ejemplo, en términos de jornada laboral, ya que solo se dispone que "los trabajadores domésticos deberán disfrutar de reposos suficientes para tomar sus alimentos y de descanso durante la noche" [...] Asimismo, no establece la obligación del empleador de registrar al trabajador doméstico en el Instituto Mexicano del Seguro Social, sino de proporcionarle asistencia médica en caso de enfermedad, mientras no sea crónica y se recupere el trabajador" (Durin, 2013, pp.99-100).

2 Harvey (2004) nos ilustra acerca de formas añejas y nuevas de proletarización. Sin embargo, es relevante señalar que en dicha perspectiva se ha dejado de lado la esfera laboral como eje central de análisis. Por ejemplo, desde la sociología se ha abordado la dimensión laboral a partir de tipologías del empleo y de la clasificación de los mercados de trabajo, como lo hemos mencionado. Incluso se ha indagado sobre la organización en la producción tratando de demostrar cuál es la forma predominante entre fordismo, postfordismo, taylorismo o just in time. Pero los cambios anteriores han sido exami- 
agenda neoliberal el emprendedurismo y el empoderamiento son parte de una relación hegemónica que valida las condiciones de autoexplotación laboral (Sosme, 2015). En el caso de México no solo se cuenta con un discurso, sino también con la existencia del Instituto Nacional del Emprendedor, que define como emprendedores a "las mujeres y los hombres con inquietudes empresariales, en proceso de crear, desarrollar o consolidar una micro, pequeña o mediana empresa a partir de una idea emprendedora o innovadora". ${ }^{3}$ Con este discurso y práctica hegemónica, la incertidumbre laboral se mueve al terreno del individualismo; la falta de o nula estabilidad se experimenta en términos personales.

Una cuestión que deja fuera el discurso emprendedor es que la situación económica actual obliga a muchas familias a trabajar por cuenta propia. Más que por una iniciativa sustentada en una agencia estratégica de los sujetos, es una estrategia de supervivencia anclada en la pluriactividad.

Por otra parte, las condiciones de trabajo muestran cada vez más procesos de externalización, situaciones de descentralización productiva, cadenas de subcontratación, relocalización u outsourcing. "La manera en que este proceso de externalización laboral se presenta va más allá del ámbito normativo (leyes laborales), repercutiendo y modificando los procesos en que se lleva a cabo la reproducción social de los trabajadores y sus familias" (Flores y Macip, 2017).

\section{Trayectorias fragmentadas y arreglos familiares}

Si partimos de la perspectiva de la precarización de los mercados de trabajo y de las condiciones de reproducción de sectores específicos de la población en México, encontramos la necesidad teórica de reflexionar sobre las condiciones y los arreglos que permiten que ciertos sujetos se desarrollen y otros apenas subsistan.

Los artículos de María Judith Valeria Montoya García, Mónica Patricia Toledo González, y el de Andrea Bautista León y Gabriela Sánchez-Soto, en este número, muestran una acumulación de desventajas económicas y sociales. Unos autores desde el dato estadístico y otros desde el análisis cualitativo, proporcionan evidencia de la manera en que determinados sectores de población experimentan y son parte de un ejército industrial desechable.

Retomamos la categoría marxista articulada al curso de vida de dichos sectores en calidad de precarios. Es decir, trayectorias fragmentadas o ciclos de vida de los sujetos se concatenan en una transición a la precariedad; de trabajadores perma-

nados de manera aislada y en ningún momento se ha reparado en estudiarlos como una combinación de modalidades que tienden a crear formas de trabajo novedosas en el escenario de un proceso global de proletarización que incluyen a México y América Latina.

3 Véase http://www.emprendetic.gob.mx/ 
nentes en una etapa de formación a trabajadores desechables en procesos de envejecimiento; en la etapa de expansión, principalmente las mujeres acceden a trabajos de medio turno, o poca paga, porque requieren tiempo para la crianza y el cuidado de los hijos. En esta etapa las mujeres encuentran ciertas “ventajas” al poder ocupar tiempo y espacio en el cuidado de los menores.

En este sentido, se articula la precariedad de los mercados con las etapas o el curso de vida de los sujetos. Es así que transitan a ser parte de un ejército industrial desechable; por ello retomamos la categoría marxista de superpoblación relativa, en sus formas flotante, latente o intermitente. Por precariedad consideramos la propuesta de Guadarrama, Hualde y López:

...la precariedad del empleo es el mayor desafío de las sociedades contemporáneas, pues revela el establecimiento de un nuevo régimen de organización del trabajo y de integración profesional sostenido en la inseguridad social. Desde esta perspectiva, el punto crucial de la precariedad es la condición y el sentimiento de pérdida de seguridad de aquellos que lograron alguna forma de integración al mundo del trabajo y de algunos que la pretendían y no la lograron (2012, p.215).

En este caso articulamos la precariedad con la dinámica de los mercados de trabajo, en tal sentido es de utilidad el concepto de ejército industrial de reserva. En la forma flotante, de acuerdo con Marx, se ubican los trabajadores y trabajadoras requeridos en aquellos procesos de trabajo basados tanto en la intensificación como en la extensificación de la jornada de trabajo. El crecimiento absoluto de este proletariado exige una forma que aumente su número aunque sus elementos se desgasten. El reemplazo es factible porque hay un potencial de niños, adolescentes y mujeres jóvenes en condiciones económicas y sociales precarias (Roseberry, 1997; Marx, 1995).

Vislumbramos bajo esta forma trabajadores y trabajadoras que, por cuestiones de generación y de género, resultan ser una fuerza de trabajo reemplazable; por ejemplo los niños y las niñas, los adolescentes, así como aquellas mujeres que en el momento del casamiento o la llegada de los hijos no pueden evitar ausentarse de manera permanente del trabajo por contar con pocas redes sociales o no contar con ellas en absoluto. Cierto tipo de mercados de trabajo, por los procesos de trabajo y las condiciones laborales, requieren y reclaman contratar fuerza de trabajo joven, antes que los ritmos y que dichos procesos la deterioren al grado de ser inservible. En este rubro podemos ubicar, por ejemplo, el trabajo en la industria maquiladora o el trabajo doméstico retribuido, condicionado a los ciclos vitales de las familias que las emplean y a las políticas laborales y migratorias (Flores, 2010; Durin, 2013; Aguilar, 2013).

En la forma intermitente se encuentran los trabajadores en activo, pero con una base de trabajo muy irregular. "Esta categoría brinda así al capital un receptáculo inagotable de fuerza de trabajo disponible” (Marx, 1995, p.544). 
Su nivel de vida desciende por debajo del nivel normal medio de la clase obrera, y esto es precisamente lo que la convierte en instrumento dócil de explotación del capital. Sus características son: máxima jornada de trabajo y salario mínimo. Bajo el epígrafe del trabajo domiciliario nos hemos enfrentado ya con su manifestación fundamental (Marx, 1995, pp.544-545).

Ahora bien, la población inscrita como ejército industrial de reserva deja de ser relativa para convertirse en desechable, bajo determinadas condiciones.

Si bien el ejército de reserva continúa siendo el eje fundamental sobre el cual se establece la ley de la oferta y la demanda, así como el control de los salarios, hay grandes sectores poblacionales que están desapareciendo sin afectar a las formas de organización capitalista. Muchos trabajadores acaban siendo atrapados por el mercado informal o por las redes del crimen, otros tienen que desplazarse de las zonas rurales e integrarse a la creciente fuerza de trabajo urbano así como migrar a otros países (Carreras, 2009, pp.256).

De acuerdo con estas características es que retomamos la propuesta de Ellis sobre la definición de reproducción social, es decir, el conglomerado de relaciones sociales tanto materiales como culturales; las cuales se renuevan a través del tiempo, incidiendo en las vivencias de los miembros de la sociedad en diversas dimensiones (Ellis, 1992, en Cáceres, 1995).

La reproducción social simple en una sociedad capitalista transita a ser ampliada. Es simple cuando la reproducción de la fuerza de trabajo consiste en renovar su capacidad para que se presente al día siguiente a un mercado de trabajo, el cual solo requiere una mano de obra hábil y diestra para ejecutar determinadas tareas, un caso puede ser la industria maquiladora de prendas de vestir. En este caso el capital no requiere invertir en la fuerza de trabajo mediante capacitaciones, instrucción media, no interesa para llevar a cabo el proceso de producción que dicha fuerza de trabajo cuente con un nivel de preparación básico. Otro caso es el de la fuerza de trabajo de los sujetos en proceso de envejecimiento, como el que describe Mónica P. Toledo González en este número.

Por otra parte, lo que se vislumbra en los datos cuantitativos: nivel salarial, número de horas de trabajo, índice de la canasta básica, rotación laboral, enmarca a gran parte de la población bajo la categoría de desechable. Los sectores de población que se presentan en esta serie de artículos son una muestra de ello, sectores que bajo una acumulación de desventajas solo logran alcanzar una reproducción social simple.

Bajo dichas condiciones es que sortean una serie de decisiones que, si bien son individuales, obedecen a procesos sociales complejos. Las estrategias que logran fincar son parte de los procesos de intensificación y extensificación que se enmarcan en un régimen de superexplotación laboral. Entendemos por superexplotación laboral los mecanismos que posibilitan una mayor explotación de la fuerza física del trabajador, en contraposición a la explotación de su productividad, “y tiende 
normalmente a expresarse en el hecho de que la fuerza de trabajo se remunere por debajo de su valor real" (Marini, 1986, p.92). Por ende, la superexplotación es la intensificación y extensificación de la jornada de trabajo, con el mismo o con un salario menor. La fuerza de trabajo renueva su capacidad de trabajar bajo condiciones decadentes. Un salario insuficiente o un proceso de trabajo con sobredesgaste (sea por la prolongación de la jornada laboral, sea por la intensificación del trabajo) que acorten el tiempo de vida útil total constituyen casos en donde el capital se está apropiando hoy de años futuros de trabajo. En definitiva, estamos ante procesos de superexplotación (Osorio, 2003, p.44).

Nuestra perspectiva parte de comprender la segmentación y segregación de los mercados laborales en el contexto neoliberal como un discurso de nombrar los despojos de una manera políticamente correcta. La segmentación y la segregación de los mercados de trabajo se articulan a clase, género, etnia, generación. Es así que podemos entender que si los empleos se precarizan se feminizan, si los empleos pertenecen al sistema maquilador se constituyen en trabajos en donde encontramos frases cotidianas que expresan el racismo y el sexismo cotidiano como: "solo los indios trabajan en ellos" o "solo es un espacio para mujeres".

El análisis de estos discursos que se van encontrando es parte de estructuras de sentir más amplias. El concepto de estructuras del sentir alude a la manera en que las personas interpretan su mundo inmediato y las formas que van adquiriendo en la práctica social cotidiana. El interés es hacia los significados y valores tal como son vividos y sentidos activamente, y las relaciones existentes entre ellos. "Una estructura del sentir es una hipótesis cultural derivada de los intentos por comprender tales elementos y sus conexiones en una generación o un período, con permanente necesidad de retornar interactivamente a tal evidencia" (Williams, 1980, p.155).

El lenguaje, los gestos, como los signos, son relevantes e intervienen en delinear a un tipo particular de persona: un sujeto historizado (Narotzky \& Smith, 2006, pp.5-6). Sin embargo, Williams menciona que no cualquier experiencia debe considerarse para el análisis cultural sino aquellas que pueden ser residuales o emergentes en los límites que ponen en entredicho el orden establecido.

Proponemos, a partir del concepto de estructuras del sentir, poner atención en aquellas experiencias en las que el propio sujeto, a partir del género y la generación, se concibe en un mundo laboral precario; en síntesis, cómo se constituyen o emergen ante un proceso de proletarización neoliberal.

Si son trabajos de medio tiempo o de contratación temporal, son empleos para el sector de jóvenes. En los trabajos de autoservicio, es el sector de personas de la tercera edad que fungen como empacadores en los supermercados. En este sentido es que se articulan equivalencias precarias: trabajos precarios para sujetos políticos precarios. 
En síntesis, la estructuración de los mercados de trabajo en México se basa en una segmentación por factores de clase, de etnia y de género. En concordancia con Macip, "estamos frente a la segmentación por líneas étnicas de la súper población relativa sobrante en mercados laborales. Sean flotantes, latentes u obsoletos, los contingentes del ejército industrial de reserva se diferencian no solo en tanto proletariado, sino que las diferencias de su conflictiva historia étnica funcionan como subsidios al capital" (Macip, 2015, p.4).

En nuestra discusión sobre la dinámica actual que presentan los mercados de trabajo definidos como precarios es fundamental considerar la función del Estado, su papel de regulador entre capital y trabajo, en el contexto del Estado benefactor; en el caso de México podemos ubicar dicho período en la década de los cuarenta, con la aplicación del modelo de sustitución de importaciones; posteriormente, con el neoliberalismo, dicha regulación entre capital y trabajo se reestructura como parte de las reformas económicas de los años ochenta del siglo xx.

Muchas de las estrategias que actúan como paliativos de la precarización laboral se fincan en los arreglos familiares, y presentan en la mayoría de los hogares una pluriactividad y nula conciliación laboral entre el hogar y el trabajo. Por ello es de suma importancia explorar dichas estrategias para remontar estos procesos, específicamente las que surgen en los arreglos familiares. Enfatizando la importancia del trabajo reproductivo a partir de un análisis interseccional de experiencias de sujetos en condiciones de vulnerabilidad: mujeres indígenas, adultas mayores, empleadas domésticas y cuidadoras.

\section{Los retos del trabajo femenino en México}

Reflexionar en torno a los procesos de precarización experimentados en las familias y la necesidad de entender los arreglos que se desarrollan contribuye a entender el peso de las redes sociales, en especial el de las familiares, y la interacción que se establece entre sus integrantes. Además, la información sobre las características sociodemográficas de ciertos sujetos femeninos nos da información acerca del uso de tiempo, de los cambios y persistencias en la división sexual del trabajo; además nos sitúan en un debate amplio sobre el trabajo femenino en América Latina.

El estudio de la incorporación de la fuerza de trabajo femenina ganó notoriedad a partir de la década de los noventa. Autoras como María Eugenia de la O y Rocío Guadarrama vinculan lo anterior con tres procesos: "de reestructuración económica, de flexibilización de las relaciones laborales y de globalización de los mercados" (2006, p.437). El trabajo femenino está marcado por desigualdades de género que hay que considerar y que terminan por ahondar la brecha entre varones y mujeres, por lo que hay que considerar cómo las mujeres se enfrentan a 
la segregación ocupacional, la precarización del trabajo, las dobles jornadas y la discriminación salarial, tal como lo discuten Andrea Bautista León y Gabriela Sánchez Soto en este número. Estamos de acuerdo con De la $\mathrm{O}$ y Guadarrama en la consideración sobre la importancia de las desigualdades de género en el debate de la flexibilidad laboral, así pues habría que considerar:

a) Los procesos de trabajo, la división sexual del trabajo y las oportunidades laborales de las mujeres; b) las nuevas formas y temporalidades del empleo y del trabajo, que se asocian con un panorama de precariedad de género $\mathrm{y} ; \mathrm{c}$ ) los riesgos y oportunidades de las mujeres en el contexto de la división internacional del trabajo y la globalización (De la O Guadarrama, 2006, pp.446-447).

Considerar la división sexual del trabajo es importante ya que no solo refiere a un proceso económico sino que establece:

...las normas que regulan sus trabajos, las representaciones de lo femenino y lo masculino, el reconocimiento social y el poder para expresar sus opiniones y desarrollar sus proyectos personales y colectivos. Incide también en la identidad de los géneros, es decir en las pautas socialmente esperadas de las conductas, valores y expectativas de las personas según su sexo, y que son asumidas como naturales (oIT, 2000, p.B3).

La contribución de integrar la categoría género permite analizar críticamente ciertas dicotomías, como las de producción/reproducción y público/privado. A decir de Oliveira y Ariza, contribuyen a desnaturalizar desigualdades ya que "se cuestiona la visión del ámbito doméstico y reproductivo como femenino, privado y opuesto a la esfera de lo público-productivo, entendido como lo masculino, y la aceptación de la división sexual del trabajo (hombres-proveedores, mujeres-amas de casa) como algo natural" (2002, p.651).

Así pues, el trabajo femenino está relacionado con los procesos de reproducción social, y en particular de la fuerza de trabajo ya que, como lo mencionan Oliveira y Salles, esta "además de cubrir el desgaste físico y psicológico del trabajador en tanto individuo, abarca también su reposición generacional, y debe ser remitido a la reconstitución del conjunto de capacidades en el nivel societal" (Oliveira \& Salles, 2002, p.626).

Según Sonia Parella Rubio, la reproducción comprende tres niveles: "la reproducción biológica, la reproducción de la fuerza de trabajo y la reproducción social" (2003, p.43); a pesar de que la maternidad sea asociada al ámbito natural de la reproducción, las tareas de cuidado han sido, de igual forma, biologizadas y asignadas a las mujeres por una lógica patriarcal. Además del cuidado de los hijos, las mujeres han cubierto "las actividades asociadas con el mantenimiento diario de la fuerza de trabajo pasada, presente y futura" (Parella, 2003, p.43).

Las jerarquías, que se han naturalizado, perviven de tal forma que el cuidado infantil y las tareas del trabajo doméstico se han asignado arbitrariamente a las mujeres, de tal suerte que no es extraño que en su gran mayoría ellas sean quienes 
asignan las tareas domésticas y del cuidado a las otras mujeres. Aquí nos remitimos a las ideas de María de Jesús Izquierdo, quien afirma que el "cuidado y sexismo van de la mano" (2003, p.26).

El Colectivo Precarias a la Deriva ha definido pertinentemente el trabajo del cuidado como "las prácticas orientadas a la gestión y el mantenimiento cotidiano de la vida y la salud, a hacerse cargo de los cuerpos sexuados, reconociendo que estas prácticas están atravesadas por (des)afectos y que constituyen en sí mismas relaciones" (2006, p.108).

Así pues, las problemáticas condiciones laborales se enlazan con cuestiones propias a que el trabajo que realizan remite a un espacio "privado" y es considerado muchas veces un trabajo íntimo. En el caso del trabajo íntimo se puede observar cómo se complejiza la intersección entre el dinero y el amor, ya que el trabajo doméstico y el cuidado como actividad primordial remite a la intimidad, es decir, a un "estado material, afectivo, psicológico y encarnado". El conocimiento generado por el trabajo íntimo incluiría "elementos como secretos compartidos, rituales interpersonales, información corporal, percatarse de vulnerabilidades personales y memorias compartidas de situaciones embarazosas", e "involucra interacciones encarnadas y afectivas en el servicio de la reproducción social” (Boris y Parreñas, 2010).

Las condiciones de intimidad del trabajo del cuidado, que implica hasta una relación "familiar", contrastan con las condiciones laborales en las que se realizan, ya que la búsqueda de minimizar costos y maximizar ganancias hace que se vea con más precisión cómo la esfera de los cuidados es un enclave de la precarización de la existencia.

Las condiciones laborales no son ajenas a las relaciones de género; al contrario, son un componente esencial para reflexionar el trabajo remunerado o no remunerado en el interior de las familias. Pensar el género nos ayuda a visibilizar la desigualdad en los mercados de trabajo ya que, como menciona Judith Butler, el género no es una esencia o una posesión, sino que "el género requiere e instituye su propio y distinto régimen regulador y disciplinador" (2004, p.68), y deviene norma porque rige la inteligibilidad social, esto es, "la norma marca y efectúa el desplazamiento de una concepción de poder como: a) una serie organizada de restricciones, y b) un mecanismo regulador" (Butler, 2004, p.80). A decir de Encarnación Gutiérrez Rodríguez: La delegación del trabajo doméstico y del cuidado a otra mujer recrea y sedimenta la división social del trabajo basada en la lógica heteronormativa. Es con base en esta lógica que se organizan las relaciones de parentesco, familiares e íntimas en la mayoría de los hogares privados. Esta lógica dicta las relaciones heterosexuales como norma principal del orden social, configurando y reafirmando nociones de feminidad y masculinidad arraigadas en la historia patriarcal Occidental (2013, p.125).

Consideramos que en el contexto neoliberal el proceso de reproducción de la fuerza de trabajo se articula con un proyecto de hegemonía selectiva (Smith, 2011). 
En dicho proyecto, un sector de la población, como se aprecia en los siguientes trabajos, pasa a formar parte de la población sobrante. Para Smith en la fase actual predomina el capital financiero, por lo que hay un proceso selectivo de poder canalizar a ciertos sectores de la población; es así que emerge un excedente de población que se integra a la población sobrante, como ejemplo está el caso de las trabajadoras domésticas, sobre el cual abundaremos.

En el trabajo doméstico asalariado no solo intervienen las relaciones de género sino que también intervienen a nivel global, como lo hemos mencionado, la acumulación del capital y las relaciones de explotación económica. No es porque "la clase sea la única forma de opresión", ya que existen otras fuentes de conflicto social, como el racismo o el sexismo. Sin embargo, es necesario pensar que el terreno de la clase "es la organización social de la producción que crea las condiciones materiales de la existencia misma" (Meiksins Wood, 2000, p.127).

Así, Meiksins Wood pone de manifiesto que la clase como relación "implica de hecho dos relaciones: la que hay entre clases y la que hay entre los miembros de la clase misma" (2000, p.110). Y más, "la desigualdad de clase existe más allá de sus representaciones teóricas" (Skeggs, 1997, p.6); la clase, según Beverly Skeggs, no solo informa sobre la subjetividad de los sujetos "sino, también es central para estos, incluso si no nos sentimos impedidos por esta o elegimos no reconocerla, o la evitamos a través de la desidentificación y el disimulo" (1997, p.7).

Su proceso de reproducción como fuerza de trabajo en acto se extiende, pues no cuenta con las prestaciones sociales, pero ante la precariedad de las condiciones de trabajo en el mercado de trabajo doméstico lo que se vislumbra es un acelerado proceso de desgaste de esta fuerza de trabajo que se extiende a una edad en que se considera ya poco productiva como valor de uso. El desgaste y su decadencia como fuerza de trabajo es lo que define Mónica P. Toledo González en este número como un proceso de envejecimiento no tanto por la edad cronológica sino por las condiciones de su precaria reproducción, en que los salarios, horas de trabajo y la incertidumbre laboral inciden en dicho envejecimiento.

La participación en el mercado laboral de este sector de trabajadoras domésticas se extiende hasta la edad de los 75 años. En tal sentido es que su dinámica de desechabilidad de fuerza de trabajo es el mecanismo en que se valoriza precariamente. Su desvalorización es lo que da sustento a la precariedad y a la existencia de este tipo de trabajo que se requiere, pero siempre bajo un esquema de precariedad.

La selectividad como proceso hegemónico se muestra en lo que presenta María Valeria Montoya en este número, en la caracterización que realiza sobre asalariados precarios y asalariado protegido. Es decir, podemos observar que las características en cuanto a definir tanto a los trabajadores como sus empleos muestran la segmentación y segregación, pero sobre todo que un grueso de la fuerza de trabajo para formar parte de un ejército industrial desechable, que se encuentra incluido pero 
en condiciones de exclusión al no contar con las condiciones estables de trabajo: salarios, prestaciones sociales, sino que su reproducción se reduce al día a día, como mano de obra desechable.

Las estadísticas dan muestra de procesos socioeconómicos que permiten observar, a partir de datos cuantitativos, procesos sociales y culturales que tienden a la precarización de la vida no solo de los sectores "vulnerables", como las personas de la llamada tercera edad, sino de sectores de población que en edad productiva no encuentran las oportunidades para el desarrollo y aplicación de sus conocimientos.

El caso de la reproducción ampliada se remite a la fuerza de trabajo que, por estar inserta en mercados de trabajo especializados, requiere mano de obra calificada que cuente con un salario que incluya no solo un ingreso sino también prestaciones sociales, un salario que permita la educación de la siguiente generación, para su inserción en un mercado de trabajo que requiere cierta calificación de su fuerza de trabajo. En tal sentido, consideramos que los sujetos que presentamos solo logran una reproducción simple.

Según el Instituto Nacional de Estadística y Geografía (INEGI, 2014a), el número de personas de 60 años y más es de 11.7 millones, ${ }^{4}$ lo que representa el $9.7 \%$ de la población total. Cabe destacar que sólo el $26 \%$ del total cuenta con prestaciones sociales y pensión, y el $74 \%$ subsiste en la informalidad. En México existe una política social asistencialista con la población envejecida, hay programas federales como el Seguro Popular, ${ }^{5}$ que proporciona atención médica para no derechohabientes, y una pensión focalizada llamada "70 y más" para quienes tengan más de 65 años y perciban menos de 1,092 pesos (74.80 dólares) mensuales; con este programa los adultos mayores reciben un apoyo de 580 pesos (39.7 dólares) mensuales, que se otorgan en entregas bimestrales.

Como se puede observar, los recursos entregados no alcanzan para costear la canasta básica alimentaria ni rural (853.60 pesos/59 dólares) ni urbana (1225.16 pesos/84 dólares), que es el mínimo de bienestar propuesto por el Consejo Nacional de Evaluación de la Política de Desarrollo Social (Coneval, 2014). Mucho menos alcanza para la canasta básica no alimentaria (transporte público, limpieza y cuidado, ocio y recreación, vivienda, etcétera).

Es así que el cuidado cotidiano no se considera en los programas sociales provistos por el Estado a nivel nacional, y generalmente este recae en particulares o en las familias de los adultos mayores. Dentro de la familia, generalmente, las tareas de cuidado son realizadas o delegadas en mujeres, como menciona Karina Batthyány:

El brindar cuidados es una actividad altamente genérica, y viceversa, es por medio

\footnotetext{
$4 \quad$ Según el Consejo Nacional de Población (Conapo, 2014), en 2050 habrá 32.4 millones de adultos mayores en México.

5 Para ver reglas de operación y población atendida: http://www.seguropopular.gob.mx/
} 
del cuidado que la identidad genérica de las mujeres es construida. La posición de las mujeres en la familia, sus oportunidades en el mercado laboral, su forma de relacionarse con parientes es definida en términos de potencialidad de brindar cuidados y de la realización de su capacidad de cuidar. Cuidado y femineidad son dos caras de la misma moneda (2004, p.51).

Cuando el cuidado de las familias es delegado en particulares dentro del mismo hogar, generalmente es en otras mujeres. Según el INEGi (2014b), en 2013 la población ocupada en México dedicada al trabajo doméstico remunerado en hogares particulares sumó más de dos millones de personas, de las cuales nueve de cada diez son mujeres. De ellas, $85.5 \%$ realiza tareas de limpieza en hogares particulares, $8.6 \%$ son cuidadoras de personas y $4.7 \%$ son lavanderas o planchadoras en casas particulares.

Cabe destacar que, como señalan Silvia López y Amaia Pérez Orozco, ${ }^{6}$ existe una tendencia en varios países a la transformación de la organización social de los cuidados que presenta "un cierto paso del familismo servilista al profesionalismo neoservilista (profesionalismo mercantilizado), sobre todo, en lo relativo al cuidado de personas con diversidad funcional y de menores, así como al mantenimiento y gestión del hogar" (2011, p.155).

Las mujeres que atienden a personas de la tercera edad y realizan trabajo del cuidado remunerado en México pueden ser profesionales (cuentan con un grado que avale sus servicios como enfermeras, especialistas en geriatría, acondicionadoras físicas, etc.) o no especialistas (mujeres que cuentan con conocimientos y habilidades relacionadas con el cuidado, pero que no han sido avaladas por instituciones educativas o profesionalizantes).

En México el trabajo del cuidado está regulado como trabajo doméstico por la Ley Federal del Trabajo en el título sexto “Trabajos especiales”. Ahí se define como trabajador doméstico aquel que "realiza una labor de aseo, asistencia, y en general, los trabajos propios o inherentes al hogar de una persona o familia" (artículo 331). ${ }^{7}$ Concordamos con Mónica Toledo González en señalar la ambigüedad del apartado concerniente al trabajo doméstico:

...primero porque está enfocado a la modalidad del trabajo doméstico de planta, dejando en el limbo a los trabajadores domésticos en modalidad de entrada por salida. Y en segundo término, si bien existen derechos contemplados en la ley para los trabajadores domésticos - aguinaldo, vacaciones, prima vacacional, jornada de trabajo, días de descanso obligatorio, cuestiones relativas a la maternidad, antigüedad - igualmente aplicables para otros trabajadores, destaca la discrecionalidad que desde la misma ley se permite (2014, p.175).

\footnotetext{
$6 \quad$ En el caso de España, pero que también se observa en México.

7 La Ley Federal del Trabajo está disponible en http://info4.juridicas.unam.mx/juslab/leylab/123/
} 
Asimismo, aquellas trabajadoras que no cuentan con credenciales para el ejercicio "profesional" de sus actividades de cuidado se insertan en el sector informal del trabajo del cuidado remunerado. Con lo que las condiciones laborales con arreglo entre particulares quedan sin contrato escrito, son "buena voluntad" de la parte contratante y en la mayoría de los casos sin ninguna prestación social.

Como lo apuntaba María Nieves Rico (2009), una cuestión sobre el envejecimiento poblacional es que plantea interrogantes impostergables sobre el cuidado. Una de las dudas es la misma concepción de los y las cuidadoras, ya que mientras que se ha extendido positivamente la idea de que la vejez es una etapa en que se necesita cuidado, se mantiene invisibilizada la cuestión de las trabajadoras que no gozan de reconocimiento laboral y que a través de una acumulación de desventajas se sitúan como sujetos vulnerables. El desfase se ancla también en la propuesta de la mejora de las condiciones del trabajo doméstico y del cuidado remunerado.

Coincidimos con Ana Rapoport sobre que el envejecimiento no "puede seguir siendo un tema secundario, ni en la agenda política ni en la sociedad en general [...] Es por ello que tampoco puede seguir considerándose un tema que debe "resolverse en el ámbito familiar" [...]" y, por el contrario, debe haber un reconocimiento "y un respaldo público (atención domiciliaria y más recursos sociales)” (2011, p.312).

Siguiendo el ejemplo uruguayo, habría que plantear que las trabajadoras del hogar son el cuarto grupo de población que requiere propuestas en torno al cuidado además de la primera infancia, personas con dependencia por discapacidad y los adultos mayores. Así pues, es necesario seguir abonando en la agenda política y académica a los debates sobre la revalorización del trabajo doméstico y la necesidad de modificar la organización social del cuidado ya que estas forman parte de los procesos de "sostenimiento de la vida" (Carrasco, 2006) y mientras no se involucre al Estado seguirá siendo contemplado como un arreglo familiar particular.

\section{Conclusiones: imbricaciones de clase, género y generación}

Nuestra propuesta contempla una perspectiva local-global tanto del proceder de ciertos mercados de trabajo como de la población inserta en estos. Es local ya que argumentamos a partir de casos específicos, documentados en los trabajos de Montoya, Toledo, así como el de Bautista y Sánchez Soto, la precariedad y las formas de reproducción social en México. Es global porque las formas y prácticas del proceder de los mercados laborales se incrustan en una dinámica hegemónica, en que determinadas relaciones de consenso y coerción se inscriben en la actual acumulación de capital. Bajo el neoliberalismo el discurso se movilizó hacia una coherencia estructural, es decir hay una construcción del consentimiento fincada en la solidaridad, la justicia social, la libertad individual, discurso que sustituye a una fuerza 
política que mediaba o se oponía en cierta medida a los intereses del capital, como los sindicatos.

No solo los países de la periferia, también llamados en vías de desarrollo, experimentan procesos de precariedad, también los países desarrollados han visto un deterioro en el ámbito laboral. Desde esta mirada, como lo apuntamos líneas arriba, la categoría de clase debe ser retomada en los estudios sociales como una herramienta de análisis crítico para entender las emergentes formaciones de clase (Kasmir y Carbonell, 2014).

La exclusión laboral en la que ciertos sectores de la población se inscriben, como trabajadores de medio tiempo, en la informalidad, o aquellos que emprenden pequeños negocios, conduce al abandono en el análisis de la categoría de clase. La situación de dichos sectores dista de lo que en nuestro imaginario se ha impreso como parte de la clase trabajadora (Kasmir y Carbonell, 2014; Crehan, 2004). Sin embargo, consideramos que dicha incertidumbre, movilidad o rotación en la que los trabajadores se ven atrapados no debe ser entendida en términos de hibridez o identidades flexibles. Nuestra propuesta cobra relevancia al considerar a esta población como parte de un proceso de formación y situación de clase.

Crehan lanza la interrogante de por qué poner atención en el concepto de clase en donde no hay expresiones de una conciencia de clase, no hay un movimiento obrero o no existe la claridad histórica para que aquella se imponga a nuestra atención (2004: 117). Para la autora, y en concordancia con su perspectiva, debemos vislumbrar, a partir de las experiencias, las condiciones en que hombres y mujeres viven las relaciones productivas, es decir antes de ver al trabajador en el piso laboral debemos indagar sobre el proceso histórico en que emergen como formación de clase.

Siguiendo la propuesta de Kasmir y Carbonell (2014), en la actual reestructuración del capital se está produciendo un rango diverso de nuevas relaciones laborales: informales, criminalizadas, militares e infantiles. Nuevas formaciones de clase transnacionales emergen. Las jerarquías laborales tan comunes con las que se pensaba al trabajador industrial o al de servicios se encuentran en una etapa de elaborar, rehacer y deshacer.

Como lo apuntan Kasmir y Carbonell desde el sentido común, "las imágenes culturales y la comprensión de la clase” son imágenes de larga duración, mapas de clase en los que quedamos atrapados, que contemplan lo que heredamos del ámbito familiar, el barrio, el sindicato, la escuela y el cine. Una de las reflexiones que se deben considerar es que más allá de emplear, bajo este escenario de precariedad, diferentes tipologías, como las que propone la oIT, habrá que poner de manifiesto las formaciones de clase desde una mirada crítica y a través del estudio de las relaciones y condiciones laborales, la experiencia de estas en la cotidianidad de los trabajadores, cómo podemos avanzar y retomar la categoría de clase.

Ahora bien, la clase, como herramienta analítica, nos permite dilucidar las ex- 
periencias de los trabajadores, articulando el género, la etnicidad y la generación. Para el caso que se documenta en los siguientes trabajos de este número es notorio cómo el género y la generación son parte de lo que Sider denomina subsidios al capital. No solo se requiere la explotación de la fuerza de trabajo para llevar a cabo la acumulación de capital, también se requiere la acumulación de diferencias. En este sentido, "las jerarquías que se construyen a partir de género así como de raza, generación y de edad, son constituyentes del dominio de clase y de la formación del proletariado moderno" (Federici en Kasmir y Carbonell, 2014: 11). Desde la perspectiva de Crehan, debemos poner atención en las estructuras del sentir, aquellas vivencias que se van convirtiendo en sentido común.

Por otra parte, y para pensar los arreglos familiares, concordamos con Encarnación Gutiérrez Rodríguez y Cristina Vega, quienes señalan que al desnaturalizar el trabajo doméstico y del cuidado "se hacen visibles los procesos de producción de la vida y se abre un cuestionamiento tanto de la organización social [...] como de las condiciones sociales, éticas y políticas que hace que una vida sea digna de ser vivida" (2014, p.17).

La organización social contemporánea está circunscrita al modelo económico y social que ha adoptado el Estado-nación, que es el neoliberal, por lo que no es posible pensar los cuidados al margen de ello. La importancia de señalar al Estado como un actor en este proceso radica en que este interviene activamente a partir de la omisión o en la regulación laboral y en una posible inversión en política social con enfoque de cuidados.

Habrá que pensar una interdependencia en el cuidado, reconocer su importancia, involucrar a los diversos niveles de gobierno para garantizar la protección legal contra los despidos injustificados, sobre la atención, la conciliación, el uso de tiempo, y se debe trabajar de cerca con los empleadores/as para sensibilizarlos sobre la necesidad de extender derechos sociales a las trabajadoras y revertir un régimen injusto del cuidado.

\section{Referencias}

Aguilar Pérez, M. (2013). Otredad solicitada: reclutamiento y promoción de au pairs latinoamericanas ante la demanda de trabajo del cuidado en Estados Unidos. Buenos Aires: Consejo Latinoamericano de Ciencias Sociales (CLACSO).

Batthyány, K. (2004). Cuidado infantil y trabajo: ¿un desafío exclusivamente femenino? Una mirada desde el género y la ciudadanía social. Montevideo: Centro Interamericano para el Desarrollo del Conocimiento en la Formación Profesional (Cinterfor/ort).

Boris, E. \& Parreñas, R. (eds.) (2010). Intimate labors: cultures, technologies, and the politics of care. Stanford: Stanford University Press. 
Butler, J. (2004). Deshacer el género. Barcelona: Paidós.

Cáceres. D. (1995). Estrategías campesinas en sociedades rurales contemporáneas. Revista de la Facultad de Agronomía (Universidad Nacional de Buenos Aires) 15(1), 67-72.

Carrasco, C. (2006). La economía feminista. Una apuesta por otra economía. En Vara, M. J. (coord.), Estudios sobre género y economía. Madrid: Akal.

Carreras, N. (2009). Vestidas, teiboleras y ficheras: vacíos legales, feminidad y proletarización en la ciudad de Puebla. Tesis de doctorado en sociología, Instituto de Ciencias Sociales y Humanidades de la Benemérita Universidad de Puebla. Puebla, Puebla.

Celis, J. C. \& Valencia Olivero, N. Y. (2011). La deslaborización en los supermercados colombianos. En Pacheco, E., De la Garza, E. \& Reygadas, L. (coords.), Trabajos atípicos y precarización del empleo (pp.341-364). México: El Colegio de México.

Crehan, K. (2004). Gramsci, cultura y antropología. Barcelona: Edicions Bellaterra.

De la Garza Toledo, E. (2015). Neoliberalismo y diversidad de corporativismos. Cuadernos del CENDES, 32(90), 35-62.

De la O, M. \& Guadarrama, R. (2006). Género, procesos de trabajo y flexibilidad laboral en América Latina. Teorías sociales y estudios del trabajo: nuevos enfoques. México: Anthropos, Universidad Autónoma Metropolitana (UAM).

Durin, S. (2013). Servicio doméstico de planta y discriminación en el área metropolitana de Monterrey. Relaciones, xxxiv(134), 93-129.

Durin, S. (2009). En Monterrey hay trabajo para mujeres. Procesos de inserción de las mujeres indígenas en el área metropolitana de Monterrey. México: Comité Regional Norte de Cooperación con la Organización de las Naciones Unidas para la Educación, la Ciencia y la Cultura (unesCo), Centro de Investigación y Estudios Superiores en Antropología Social (CIESAS), Comisión Nacional para el Desarrollo de los Pueblos Indígenas (CDI).

Ellis, F. (1992). Peasant economics - Farm, households and agrarian development. Cambridge: Cambridge University Press.

Flores Morales, M. L. (2010). Procesos de proletarización. Generación y género en la dinámica del sistema putting out de la industria maquiladora en la región de Tehuacán, Puebla. Tesis de doctorado en antropología social, Centro de Investigación y Estudios Superiores en Antropología Social. Ciudad de México.

García, B. (2011). Las carencias laborales en México: conceptos e indicadores. En Pacheco, E., De la Garza, E. \& Reygadas, L. (coords.), Trabajos atípicos y precarización del empleo (pp.81-113). México: El Colegio de México.

Guadarrama, R., Hualde, A. \& López, S. (2012). Precariedad laboral y heterogeneidad ocupacional: una propuesta teórico-metodológica. Revista Mexicana de Sociología, 74(2), 213-243.

Gutiérrez Rodríguez, E. (2013). Trabajo doméstico-trabajo afectivo: sobre heteronormatividad y la colonialidad del trabajo en el contexto de las políticas migratorias de la UE. Revista de Estudios Sociales, 45, 123-134. 
Gutiérrez Rodríguez, E. \& Vega, C. (2014). Nuevas aproximaciones a la organización social del cuidado. Debates latinoamericanos. Íconos, 50, 9-26.

Hall, S. (2015). Unas rutas "políticamente incorrectas" a través de lo políticamente correcto. Mediaciones, 14, 137-148.

Harvey, D. (2004). El nuevo imperialismo. Madrid: Akal.

Herrera, G. (2012). Género y migración internacional en la experiencia latinoamericana. De la visibilización del campo a una presencia selectiva. Política y Sociedad, 49(1), 3546. Recuperado de http://dx.doi.org/10.5209/rev_POSO.2012.v49.n1.36518

Instituto Nacional de Estadística y Geografía (INEGI) (2014a). Estadísticas a propósito del Día Internacional de las Personas de Edad (1 de octubre). Datos nacionales. Recuperado de http://www.inegi.org.mx/inegi/contenidos/espanol/prensa/Contenidos/ estadisticas/2014/adultos0.pdf

Instituto Nacional de Estadística y Geografía (INEGI) (2014b). Estadísticas a propósito del Día Internacional del Trabajador Doméstico (30 de marzo). Datos nacionales. Recuperado de http://www.inegi.org.mx/inegi/contenidos/espanol/prensa/Contenidos/ estadisticas/2014/domestico0.pdf

Izquierdo, M. J. (2003). Del sexismo y la mercantilización del cuidado a su socialización: hacia una política democrática del cuidado. Recuperado de http://www.fuhem.es/me$\mathrm{dia} / \mathrm{cdv} /$ file/biblioteca/Boletin_ECOS/10/Socializacion_del_cuidado.pdf

Kasmir, S. \& Carbonell, A. (eds.) (2014). Blood and fire. Toward a global anthropology of labor. New York: Berghahn Books.

López Gil, S. \& Pérez Orozco, A. (2011). Desigualdades a flor de piel: cadenas globales de cuidado. Concreciones en el empleo de hogar y políticas públicas. Madrid: onU Mujeres.

Macip, R. (2015). El sublime objeto de la poscolonia. En Sánchez Saldaña, K. (coord.), Diversidad cultural, territorios en disputa y procesos de subordinación (pp. 173-199). Cuernavaca: Universidad Autónoma del Estado de México.

Macip, R. \& Flores, M. (2017) Multiculturalismo y mercados laborales en el Centro Sur de México, en imprenta.

Marini, R.(1986). Dialéctica de la dependencia. México: Serie Popular Era.

Marx, C. (1995). El capital. México: FCE.

Meiksins Wood, E. (2000). Democracia contra capitalismo. México: Siglo xxI, Universidad Nacional Autónoma de México.

Narotzky, S. \& Smith, G. (2006). Immediate struggles. People, power and place in rural Spain. Berkeley y Los Ángeles: University of California Press.

Nieves Rico, M. (2009). Crisis del cuidado y políticas públicas. El momento es ahora. Presentación en el seminario Las Familias Latinoamericanas Interrogadas. Hacia la articulación del diagnóstico, la legislación y las políticas. Cepal. Recuperado de https:// www.academia.edu/2474960/Crisis_del_cuidado_y_pol\%C3\%ADticas_p\%C3\%BAblicas_el_momento_es_ahora

Oliveira, O. \& Ariza, M. (2002). Trabajo femenino en América Latina: un recuento de los 
principales enfoques analíticos. En De la Garza, E. (coord.), Tratado latinoamericano de sociología del trabajo (pp. 644-679). México: El Colegio de México, Facultad Latinoamericana de Ciencias Sociales, Universidad Autónoma Metropolitana, Fondo de Cultura Económica.

Oliveira, O. \& Salles, V. (2002). Reflexiones teóricas para el estudio de la reproducción de la fuerza de trabajo. En De la Garza, E. (coord.), Tratado Latinoamericano de Sociología del Trabajo (pp. 619-643). México: El Colegio de México, Facultad Latinoamericana de Ciencias Sociales, Universidad Autónoma Metropolitana, Fondo de Cultura Económica.

Organización Internacional del Trabajo (оIт) (2000). Equidad de género en el mundo del trabajo en América Latina. Avances y desafíos 5 años después de Beijing. Presentado a la Octava Conferencia Regional sobre la Mujer de América Latina y el Caribe, Lima, Perú. Recuperado de http://www.ilo.org/public//spanish/region/ampro/cinterfor/temas/gender/doc/cinter/equidad/index.htm

Osorio, J. (2003). Dependencia y superexplotación. Actualidad de un pensamiento radical. Estudios Latinoamericanos, 20, 39-52.

Pacheco, E., De la Garza, E. \& Reygadas, L. (2011). Trabajos atípicos y precarización del empleo. México: El Colegio de México.

Parella Rubio, S. (2003). Mujer, inmigrante y trabajadora: la triple discriminación. Barcelona: Anthropos.

Precarias a la Deriva (2006). Precarización de la existencia y huelga de cuidados. En Vara, M. J. (coord.), Estudios sobre género y economía. Madrid: Akal.

Rapoport, A. (2011). ¿Envejecer solos o solo envejecer? La exclusión social en la tercera edad. En Di Virgilio, M., Otero, M. P. \& Boniolo, P. (coords.), Pobreza urbana en América Latina y el Caribe. Buenos Aires: Facultad Latinoamericana de Ciencias Sociales.

Roseberry, W. (1997). Marx and anthropology. Annual Review of Anthropology, 26, 25-46.

Skeggs, B. (1997). Formations of class and gender. Becoming respectable. London: Nottingham Trent University.

Smith, G. (2011). Selective hegemony and beyond-population with "no productive function": a framework for enquiry". Identities: Global Studies in Culture and Power, 18: 2-38

Sosme, M. A. (2015). Tejedoras de esperanza. Empoderamiento en los grupos artesanales de la Sierra de Zongolica. México: El Colegio de Michoacán.

Toledo González, M. P. (2014). Entre muchachas y señoras. Arreglos particulares en el trabajo doméstico remunerado en México. Tesis doctoral, Centro de Investigaciones y Estudios Superiores en Antropología Social. Ciudad de México.

Yeats, N. (2005). Global care chains: a critical introduction. Global Migration Perspectives, 44.

Williams, R. (1980). Marxismo y literatura. Barcelona: Ediciones Península. 